\title{
Transferências Federais no Brasil em 2006: Uma Análise de Desequilíbrios Vertical e Horizontal
}

\author{
Angelo José Mont' Alverne Duarte ${ }^{-}$ \\ Alexandre Manoel Angelo da Silva ${ }^{2}$ \\ Everaldo Manoel $\mathrm{Luz}^{3}$ \\ José Carlos Gerardo ${ }^{4}$
}

Resumo: Este artigo visa contribuir para a discussão sobre o federalismo fiscal brasileiro. Nesse sentido, este artigo possui dois objetivos específicos. Primeiro, identificar de que modo as transferências do governo federal supre a brecha fiscal vertical. Segundo, analisar se há desequilíbrio horizontal nas transferências federais do Sistema Único de Saúde. Após a análise empírica, baseada em dados de 2006, infere-se que o vigente esquema de transferências federais não supre adequadamente a brecha fiscal vertical existente na federação brasileira. Ademais, infere-se que a União não utiliza o critério de equidade no acesso aos serviços públicos de saúde.

Palavras-chave: brecha fiscal vertical; equidade; SUS.

JEL: $\mathrm{H} 71, \mathrm{H} 77$. 


\title{
Federal transfers in Brazil in 20o6: an analysis of vertical and horizontal inequalities
}

\begin{abstract}
This article is about the Brazilian fiscal federalism. It has two objectives. First, we are interested in identifying whether and how the federal government transfers to subnational governments help to close what is known in the literature as vertical fiscal gap. Second, we are interested in discovering if the federal fiscal transfers to the Brazilian public health system (SUS) lead to horizontal inequalities, meaning that per capita expenditure are higher in some regions than in others. Based on a database for 2006, we show that the current federal government transfers to subnational governments neither close the vertical gap nor lead to equal access to health services in Brazil.
\end{abstract}

Keywords: vertical fical gap; equity; brazilian public health system (SUS)

JEL: $\mathrm{H}_{71}, \mathrm{H} 77$.

Introdução ${ }^{5}$

As transferências fiscais intergovernamentais representam importante mecanismo de equilíbrio das finanças das unidades subnacionais, tanto nos países em desenvolvimento quanto nos países industrializados, mas principalmente naqueles que pela extensão territorial se organizam como federações. No Brasil, essas transferências responderam por aproximadamente $42 \%$ das despesas dos governos subnacionais no ano de 2006. Todavia, é importante considerar que, além de financiar as despesas dos entes subnacionais, essas transferências criam mecanismos de responsabilização ${ }^{6}$ e incentivos que afetam o desempenho fiscal, a prestação de contas dos governantes aos cidadãos e a eficiência e a equidade no acesso aos serviços públicos.

Em tese, há ao menos duas justificativas econômicas para efetuar essas transferências. A primeira advém dos ganhos de eficiência obtidos na arrecadação dos tributos pelo governo central, que pela amplitude da base tributária concentra maior volume de recursos, e da capacidade dos governos locais de proverem a maior parte dos serviços públicos de forma mais eficiente. Isso origina um descompasso contábil da arrecadação de recursos versus a necessidade de

\footnotetext{
5 Os autores agradecem às contribuições de dois pareceristas anônimos que efetivamente contribuíram para a melhoria deste 5 artigo.

6 Neste artigo, as expressões responsabilização e accountability são usadas como sinônimos.
} 
prover serviços públicos nas Unidades da Federação (UF), que se denomina brecha fiscal vertical, ${ }^{7}$ segundo a literatura sobre finanças públicas.

A segunda, que é um tanto quanto subjetiva, ${ }^{8}$ mas não menos importante que a outra, justifica-se na provisão de serviços públicos com um padrão mínimo de qualidade em todas as UF circunscritas a um mesmo país. Em outras palavras, qualquer indivíduo independentemente da localidade onde resida, considerando-se as fronteiras de um mesmo país, deveria ao menos acessar um serviço público com padrão de qualidade mínimo. Quando a provisão de serviços públicos é oferecida de forma heterogênea no espaço geográfico de um país, ocorre o que na literatura é conhecido como desequilíbrio horizontal.

Portanto, as transferências intergovernamentais visam diminuir os desequilíbrios verticais e horizontais que surgem em uma federação. Porém, em muitos casos, é possível não existir uma preocupação sobre o desenho do sistema de transferências efetuadas com vistas a cobrir desequilíbrios verticais e/ou horizontais.

Nesse caso, as transferências não ratificariam os resultados esperados. A título de ilustração, segundo Guedes \& Gasparini (2007), no Brasil, um aumento da participação das transferências nas receitas totais do município aumenta o tamanho do governo, o que seria bastante justificável, pois o sistema brasileiro de repartição das transferências não possui qualquer mecanismo indutor de eficiência.

Assim, ainda que as transferências intergovernamentais sejam utilizadas apenas para fechar a brecha fiscal vertical, determinando o equilíbrio orçamentário para todos os níveis de governo depois de efetuadas a arrecadação dos tributos e a alocação das despesas entre as esferas de governo, tais transferências podem não alcançar esses objetivos, se não forem providas por meio de um desenho que induza à eficiência.

Há também sistemas de transferências que promovem maior equalização no acesso aos serviços públicos de qualidade que outros, em decorrência das diferenças nas estruturas de incentivos ensejadas pelos respectivos sistemas. De fato, conforme já mencionado, além de financiar despesas das esferas de governo, as transferências intergovernamentais criam incentivos e mecanismos de accountability que afetam a gestão fiscal, a eficiência e a equidade da prestação dos serviços públicos à população.

Dessa forma, ao avaliar a estrutura dos programas de transferências, é essencial se ater aos incentivos que o governo central emite aos governos locais

\footnotetext{
7 Como mencionado, a brecha fiscal vertical seria definida como a deficiência de receita que se origina em função do desequilíbrio entre a receita própria e a necessidade de gastos, o que é típico dos níveis inferiores de organização do governo. Em geral, implica desequilíbrio fiscal vertical, que é a situação na qual a brecha fiscal vertical não é adequadamente tratada, seja pela redefinição de responsabilidades ou por meio das transferências fiscais.

8 A subjetividade encontra-se no fato de essa justificativa supor que a função de bem-estar do país leve em consideração a equidade no acesso aos serviços públicos.
} 
e,indiretamente, às populações residentes nas diferentes regiões do país, pois os resultados obtidos por meio das transferências intergovernamentais podem ser positivos ou negativos, dependendo da estrutura de incentivos engendrada na montagem do sistema de transferências. ${ }^{9}$

Diante do exposto, este artigo pretende dar alguma contribuição à discussão sobre o federalismo fiscal brasileiro. Nesse sentido, este artigo possui dois objetivos específicos. Primeiro, identificar de que modo as transferências do governo federal supre a brecha fiscal vertical. Segundo, analisar se há desequilíbrio horizontal nas transferências para a consecução do Sistema Único de Saúde (SUS).

Destaque-se que, na análise de desequilíbrios horizontais, não seria possível no curto espaço disponível para este texto analisar todas as transferências. Em decorrência dessa limitação, escolhemos analisar as transferências do SUS. Além de o SUS apresentar explicitamente como um de seus princípios a equidade, justifica-se essa escolha do SUS porque, em 2006, ano em que foram coletados os dados, as transferências para o SUS totalizaram R \$ 20,65 bilhões, ou $0,8 \%$ do PIB, equivalente a 12,5\% das transferências correntes efetuadas pelas três esferas de governo (de forma consolidada), o que denota constituírem as transferências do SUS importante mecanismo de equidade ou iniquidade do federalismo fiscal brasileiro.

Por conseguinte, no intuito de efetivamente alcançar os dois aludidos objetivos específicos, além desta introdução, este artigo está estruturado em mais quatro seções. Na próxima seção, detalham-se os fundamentos econômicos das transferências intergovernamentais e elabora-se a tipologia das transferências intergovernamentais. Na seção 3, aplica-se a taxonomia elaborada na seção 2 às principais transferências intergovernamentais vigentes no Brasil em 2006. Na seção 4, mostram-se estimativas da brecha vertical no federalismo fiscal brasileiro e discute-se a equidade horizontal das transferências do SUS. Por fim, na seção 5, algumas conclusões são apresentadas.

\section{Fundamentos econômicos das transferências e tipolo- gia das transferências intergovernamenntais ${ }^{10}$}

\subsection{Perspectiva econômica do federalismo}

Entende-se por federalismo a forma de organização dos estados caracterizada pela repartição hierárquica de poderes. De fato, a divisão de direitos e obrigações entre pelo menos dois níveis verticais de governo, por exemplo, entre um nível central e dois ou mais níveis locais. O termo federalismo contém duas

9 Em estudo empírico realizado para o Brasil, Blanco (2000) mostra que a descentralização ocorrida após a Constituição de 1988 conduziu a um contexto de perda do controle da política macroeconômica por parte do governo central.

10 A principal fonte bibliográfica utilizada para a elaboração desta seçâo é o livro de Shah e Boadway (2006). 
dimensões complementares: a política e a econômica. A dimensão política está relacionada à origem histórica das federações, a qual ocorre no momento em que ideais democráticos precisam ser inseridos em uma sociedade culturalmente diversificada, sem que isso destrua a unidade territorial.

A dimensão econômica, que é o foco deste trabalho, está vinculada basicamente à alocação de recursos. Segundo Mendes (2005), há que se diferenciar federalismo de federalismo fiscal. De fato, segundo esse autor, o termo federalismo, desacompanhado do adjetivo, diz respeito à divisão de poderes políticos e constitucionais entre os diferentes níveis de governo, indo muito além da mera divisão de tarefas administrativas. Nesse sentido, trataremos neste texto do federalismo fiscal.

Em uma federação, as alocações de poderes podem ocorrer de cima para baixo em um movimento centralizador no qual as diversas esferas subnacionais abdicam de parte de seus poderes em prol de um governo central; ou, de baixo para cima, em um movimento descentralizador, no qual o governo central delega parte de seus poderes para diversos governos subnacionais. A título de ilustração, os Estados Unidos da América constituem um exemplo de federação formada de baixo para cima, enquanto países como Índia e Austrália são exemplos de federação instituída de cima para baixo.

Conforme Giambiagi \& Além (2008), o processo de descentralização no Brasil, iniciado nos anos 1980 e aprofundado com a Constituição de 1988, teve basicamente uma motivação política. Ainda segundo esses autores, a descentralização brasileira não foi conduzida pelo governo central, mas sim pelos estados e, principalmente, pelos municípios, através de seus representantes no legislativo federal.

Nesse contexto, no vigente federalismo fiscal brasileiro, o Brasil seria exemplo de uma federação híbrida, já que possui um governo central com forte capacidade de alocação de recursos, ao mesmo tempo em que detém entes subnacionais com plena autonomia para alocar seus recursos. Ao considerarmos a dimensão política, notamos que essa hibridez reflete-se no fato de que as unidades subnacionais mais frágeis sob o ponto de vista econômico, por exemplo, em termos de PIB per capita, enquadram-se no regime de cima para baixo, no que tange à consecução de acordos e alocação de recursos discricionários, enquanto as mais fortes enquadram-se no regime de baixo para cima.

\subsection{Fundamento teórico para a arrecadação das receitas nos governos centrais}

Um problema normativo importante em um país com organização federativa é a distribuição das competências tributárias entre os vários níveis de governo. A primeira questão a ser equacionada é a escolha do critério para essa distri- 
buição. Segundo a teoria econômica da tributação ótima, a distribuição das competências deve ser feita de tal modo que o bem-estar da sociedade como um todo seja maximizado. Dessa forma, o arranjo institucional que permitiria a cada membro da federação escolher livremente seus tributos não seria a solução adequada para a sociedade, visto que daria margem a uma série de efeitos negativos provenientes de impostos ineficientes, que redundaria em perda de bem-estar para a coletividade.

Conforme os princípios de eficiência propostos na teoria da tributação ótima, Mcluren (1983) elaborou um desenho de sistema tributário para um país organizado sob a forma de federação, cujas principais conclusões sobre a distribuição das competências tributárias são as seguintes:

- impostos sobre fatores de produção com grande mobilidade são mais adequados para o governo central, enquanto impostos sobre fatores sem mobilidade são apropriados para os governos locais;

- impostos cobrados com base na residência ou no destino são mais adequados para níveis subnacionais de governo, enquanto impostos cobrados com base na origem são apropriados para o governo central;

- impostos sobre recursos naturais devem ser de competência federal;

- a capacidade fiscal pode ter uma distribuição bastante desigual entre os governos subnacionais, havendo necessidade de mecanismos de equalização horizontal, em geral implementados por meio do governo central;

- a receita tributária de vários governos subnacionais pode ser insuficiente para cobrir os seus gastos, enquanto o governo federal pode ser capaz de arrecadar mais do que precisa, havendo necessidade de um processo de transferência de recursos vertical.

Musgrave (1959) define que as três funções do governo são: estabilizadora, distributiva e alocativa. A função estabilizadora, por envolver políticas macroeconômicas que afetam a população em geral, deveria ficar a cargo do governo central. O mesmo aplica-se à função distributiva, pois está relacionada ao fluxo de capitais, de modo que poderia provocar guerra fiscal caso a distribuição fosse de responsabilidade dos governos subnacionais. Com respeito à função alocativa, Musgrave afirma estar nessa função a razão de ser do federalismo. A ideia é que impostos sobre base móvel, a fim de evitar fluxos migratórios, devem ser centralizados, enquanto impostos sobre base imóvel, bem como taxas sobre serviços específicos, devem ser descentralizados.

Assim, tanto pela análise de Musgrave (1959) quanto pela análise de Mcluren (1983) a maior parte das receitas deve ser de responsabilidade do governo central. Em outras palavras, a conclusão a que se chega é que, pelo lado do recolhimento de tributos, o mais economicamente adequado seria a centralização (salvo a existência de externalidades que atuem no sentido contrário). 


\subsection{Fundamento teórico para a relização das despesas nos governos locais}

A importância da descentralização na execução da despesa é amplamente difundida entre os especialistas em finanças públicas. $\mathrm{O}$ argumento para a tomada de decisão de descentralização é familiar aos economistas e tem estreita vinculação com o trabalho de Tiebout (1956) e Oates (1972). A descentralização é justificada pelo fato de captar com mais facilidade as preferências dos cidadãos. Um governo central unitário tende a fornecer programas públicos uniformes por todo o país; acredita-se, pois, que governos locais são capazes de responder melhor às preferências e às necessidades de seus residentes. Além disso, as vantagens com a diminuição de informação assimétrica e a maior cobrança política podem permitir aos governos locais fornecer serviços públicos a menor custo e melhor distribuídos do que se estes fossem feitos pelos governos centrais.

De acordo com Musgrave \& Samuelson (apud Tiebout 1956), não é possível determinar uma solução descentralizada eficiente, equivalente à solução de mercado do tipo first best, para a provisão de bens públicos. O problema estaria no fato de os consumidores não revelarem suas verdadeiras preferências por bens públicos, diferentemente do que ocorre perante bens privados, posto que, nesse último caso, revelam suas preferências no momento da compra. De fato, ao consumirem os bens públicos coletivamente, pagando ou não por eles, os consumidores obscurecem suas preferências, impedindo que uma solução ótima parecida com a de mercado seja identificada.

Tiebout (1956), no entanto, lembra que a revelação de preferências por bens públicos pode ser possível em níveis governamentais locais, embora não centrais. Ele argumenta que, embora não digam o quanto querem e o quanto estão dispostos a pagar por bens públicos, os consumidores ao menos escolhem a localidade em que querem viver, podendo se mudar de uma para outra a qualquer tempo, de acordo com o que cada localidade tem a lhes oferecer. Os governos locais conseguem identificar esses fluxos migratórios de modo a poder calibrar a provisão de bens públicos, conforme a atração ou repulsa que suas jurisdições exerçam nas pessoas. Por conseguinte, em nível local, a questão do bem público se reduz a um problema de escolha do tipo mercado, com a diferença de que o mecanismo de vote-by-money empregado para o bem privado é substituído por um mecanismo de vote-by-foot, representando a escolha que o consumidor faz entre as localidades. Decorre desse raciocínio a conclusão favorável a uma forma de governo mais descentralizada - economicamente mais federativa - e que imponha baixos custos à migração.

Apesar de simples, o modelo de Tiebout baseia-se em hipóteses consideravelmente restritivas e passíveis de críticas, como aponta Oates (1972):

- consumidores plenamente móveis e reativos à oferta de bens públicos; 
- consumidores com conhecimento total sobre as receitas e despesas das localidades;

- grande número de diferentes localidades disponíveis à escolha;

- desconsideração de restrições devido a emprego;

- desconsideração de externalidades positivas ou negativas entre as localidades;

- localidades têm um ótimo populacional;

- as localidades abaixo desse ótimo tentam atrair pessoas e as acima tentam repeli-las.

Apesar de esmiuçar críticas tanto às hipóteses quanto à conclusão do modelo de Tiebout, Oates (1972) reconhece que cada serviço deve ser ofertado pela esfera de governo que exerça controle sobre a extensão dos seus benefícios em termos de área geográfica mínima, de modo a internalizar os benefícios e os custos de sua prestação. Esse princípio, conhecido como "princípio da subsidiariedade”, busca a satisfação das preferências dos contribuintes e a eficiência na distribuição dos encargos. Dito de outro modo, de acordo com esse princípio, na partilha intergovernamental das despesas públicas, a maior parte caberia aos governos locais.

\subsection{Racionalidade econômica das transferências fiscais intergovernamentais}

Em consequência do que entendemos nas duas subseções anteriores, do ponto de vista econômico, em geral as receitas devem ser arrecadadas pelo governo central e as despesas devem ser efetuadas pelos governos locais, tornando-se óbvia a necessidade de se instituir transferências de recursos do nível central para os níveis locais. Esta questão é conhecida na literatura como a consecução de transferências para suprir a brecha fiscal vertical, pois, enquanto a maneira mais eficaz de arrecadação é centralizada, a mais eficaz para efetuar as despesas públicas é descentralizada via governos locais, que não possuem capacidade fiscal suficiente para suprir o conjunto dessas despesas.

Assim, do ponto de vista econômico, o resultado natural da equação resultante da divisão de responsabilidades versus concentração na arrecadação dos tributos é o desequilíbrio entre despesas e receitas entre as esferas de governo e entre as jurisdições de uma mesma esfera. ${ }^{11}$ Esse desequilíbrio pode ser corrigido por meio de um sistema de transferências intergovernamentais que permita o ajuste da distribuição de recursos entre as jurisdições de forma a perquirir o atendimento das necessidades da sociedade.

A existência desse sistema de transferência de recursos entre esferas de go${ }_{11}$ No caso brasileiro, teríamos as esferas federal, estadual e municipal, com as respectivas jurisdições estaduais e municipais. 
verno ou dentro de uma mesma esfera é fundamental para a consecução das demandas sociais, pois são as transferências que permitem não só a correção entre o volume de arrecadação e as despesas das jurisdições como também a redução das disparidades entre os governos subnacionais. Além das supostas transferências intergovernamentais para suprir os desequilíbrios verticais, a literatura sobre federalismo fiscal também recomenda as transferências para corrigir os desequilíbrios horizontais.

Em tese, a correção dos desequilíbrios horizontais é subjetiva, porquanto parte do princípio de que a função de bem-estar social maximizada contém não apenas princípios de eficiência, mas também de equidade. Nesse caso, o tratamento diferente a entes diferentes deveria ser efetuado pelo fato de que, ao suprir a brecha vertical, a sociedade estaria apenas fechando uma equação contábil. De fato, suprir a brecha vertical sem se preocupar com desequilíbrio horizontal implica escamotear o fato de que UF mais ricas teriam mais condições e facilidades para elevar a arrecadação própria, aumentando, portanto, a quantidade e até mesmo a qualidade dos serviços prestados às suas respectivas populações.

Dessa forma, ao corrigir desequilíbrios horizontais, o governo central ensejaria manter serviços públicos com padrões mínimos em todos os entes da federação, haja vista que alguns entes têm melhor acesso aos recursos naturais e demais vantagens competitivas ante os demais que compõem a federação, desfrutando de base tributária e volume de recursos mais elevados do que aqueles que não os possuem. Naturalmente, nesses entes existe mais facilidade para explorar fiscalmente as bases econômicas. ${ }^{12}$

Apesar de toda a racionalidade econômica para efetuar transferências a fim de suprir brechas verticais e desequilíbrios horizontais, não é óbvio qual seria o mecanismo mais apropriado para se efetuar essas transferências, nem a magnitude dos valores que devem ter. Uma característica importante das transferências intergovernamentais é a não existência de um padrão simples e uniforme aplicável a todos os países. Além disso, o montante apropriado de transferências de recursos depende das circunstâncias e objetivos do processo de descentralização fiscal, assim como da noção de justiça e equidade da sociedade.

12 Existe ainda a racionalidade econômica para efetuar transferências com vistas a suprir problemas decorrentes de externalidades espaciais, pois, empiricamente, como constatado em Resende \& Silva (2007), verifica-se que alguns serviços públicos geram externalidades nas unidades jurisdicionais vizinhas. Contudo, em virtude de na metodologia utilizada neste trabalho para aferirmos tanto desequilíbrios verticais quanto horizontais não utilizarmos técnicas para aferir as externalidades espaciais não expomos, no corpo principal do texto, essa racionalidade para justificar as transferências. 


\subsection{Tipologia das transferências intergovernamentais}

A criação de uma tipologia para as transferências fiscais intergovernamentais inicia-se pela observação do propósito a que se destinam. Dessa forma, essas transferências podem ser divididas em dois grandes grupos: as que possuem propósito geral e aquelas com propósito específico. A partir da definição do propósito a que se destinam, outros elementos como a colocação ou não de condicionalidades e a exigência ou não de contrapartidas financeiras são utilizados para criar essa tipologia.

As transferências com propósito geral, como o próprio nome sugere, são transferências destinadas a fomentar o orçamento geral do ente beneficiado, visando, sobretudo, preservar a autonomia local. Normalmente são expressas por lei, mas em alguns casos podem ter natureza discricionária. Do ponto de vista econômico, essas simplesmente aumentam os recursos do recebedor, que não possui qualquer obrigação junto a elas. Este é um ponto importante, pois, em virtude de razões de ordem burocrática e política, essas transferências para os governos locais tendem a incentivar um comportamento perdulário por parte desses governos. Ademais, evidências empíricas sugerem que essas transferências induzem à subutilização das bases de tributação pelos governos receptores dos recursos. ${ }^{13}$

A exigência de contrapartida (matching grant) é o elemento que serve para gerar uma subdivisão nas transferências com propósito específico, que são destinadas à consecução de determinadas ações orçamentárias. No caso das que não têm exigência de contrapartida, objetivam prover ao ente recebedor um dado nível de recursos, no intuito de que esses recursos sejam gastos em um propósito particular, sem contrapartida alguma por parte do receptor. A atratividade desse tipo de transferências encontra-se no fato de que elas permitem subsidiar atividades consideradas de alta prioridade pelos níveis mais elevados de governo, mas de baixa prioridade para os governos locais. Essas transferências podem ser obrigatórias ou discricionárias.

Em relação às condicionalidades, ${ }^{14}$ três tipos podem ser observados: i) a condicionalidade baseada no insumo (input) que especifica os tipos de gastos que podem ser custeados com os recursos transferidos; ii) a condicionalidade baseada no produto (output) que exige o alcance de determinada meta em função dos recursos transferidos e do propósito (atividade ou programa) ao qual esse recurso está associado; e iii) a condicionalidade baseada no resultado (outcome) que exige o alcance de determinados resultados em função dos

13 Ver Gasparini \& Melo (2004).

14 Vale observar que se a transferência é com propósito específico, por natureza está condicionada a algo. Assim, a condicionalidade é uma resultante natural da transferência de propósito específico. 
recursos transferidos e do propósito ao qual esse recurso está associado. ${ }^{15}$

Do ponto de vista dos mecanismos de responsabilização (accountability) e incentivos, pode ser observado que a condicionalidade baseada no insumo incentiva o controle sobre o processo em vez de incentivar sobre os produtos e/ou resultados, criando, nesse caso, custos adicionais com a burocracia. Por sua vez, a condicionalidade baseada no produto e/ou no resultado incentiva uma melhoria na responsabilização das finanças dos entes receptores dos recursos. Contudo, vale destacar que, em geral, resultados são influenciados por fatores que estão além do controle de um gestor público, de forma que seu controle pode dificultar o alcance de melhor responsabilização.

Em consequência disso, sob a ótica econômica, muitas vezes é preferível impor uma condicionalidade baseada no produto, porquanto essa concede poder aos cidadãos, haja vista que aumentam a base de informação e reduzem os custos de transação em demandar ações (corretivas), incentivando a criação de vínculos entre a concessão das transferências e o desempenho do serviço colocado à disposição dos residentes.

No que diz respeito à exigência de contrapartida, as transferências com propósito específico são mais conhecidas como programas de divisão de custos, podendo ser subdivididas em dois ramos: as transferências baseadas em insumo em que nenhum limite é imposto para a assistência disponibilizada pelo repassador dos recursos (open ended), mediante a contrapartida do receptor, e aquelas em que o repassador dos recursos define um limite até o qual as transferências são realizadas (closed ended), mediante contrapartida do recebedor. Em outras palavras, no caso de não impor limite, enquanto o receptor prover contrapartida, o transferidor pode efetuar transferências; na hipótese de impor limite, o transferidor somente transfere recursos até um determinado montante preestabelecido, mesmo que o receptor esteja determinado a aumentar a contrapartida.

As transferências com propósito específico que não colocam exigência de limite para disponibilizar recursos, mediante contrapartida do receptor, são atrativas no sentido de corrigir ineficiências na provisão de bens públicos que se originam em função de externalidades positivas, mas não resolvem problemas relacionados a desigualdades nas capacidades fiscais entre os entes. ${ }^{16}$ Do ponto de vista econômico, essas transferências podem acarretar uma situação que na literatura recebe o nome de fungibility effect, que é a situação

15 É importante diferenciar produto (output) de resultado (outcome). Nesse sentido, suponha uma transferência governamental para construir X km de estrada (produto) no trecho W-Z localizado na região alfa, que vise diminuir em Y R \$ o custo de transporte (resultado) da região alfa, é um exemplo ilustrativo.

16 Destaque-se que estamos nos referindo à desigualdade que se origina das diferenças econômicas entre os entes, e não da advinda da ausência de exploração plena da base tributária. 
em que o gasto em uma área específica aumenta menos do que deveria com a quantidade da transferência, pois há um deslocamento dos recursos que deveriam ser gastos nessa área para outros bens ou serviços públicos ou, até mesmo, para isenções fiscais.

Portanto, diante do exposto, apresenta-se na Tabela 1, sinteticamente, a taxonomia das transferências apresentadas, baseadas em Shah \& Boadway (2006).

\section{TABELA 1. TAXONOMIA DAS TRANSFERÊNCIAS}

Tipo de transferência

Geral sem contrapartida

Condicional (sem contrapartida) baseada no insumo, no produto ou no

resultado

Condicional (com contrapartida) baseada no insumo

Sem limite

Com limite

FONTE: Elaboração dos autores.

Após se analisar os fundamentos econômicos (normativos) das transferências intergovernamentais e se elaborar uma taxonomia dessas transferências, na próxima seção evidenciam-se a arrecadação de receitas e as transferências realizadas entre as três esferas governamentais.

\section{Transferências intergovernamentais: aplicação da taxonomia apresentada às transferências vigente no Brasil em 2006}

Conforme observado na seção 2, em um regime federativo, do ponto de vista normativo, a arrecadação de tributos tende a se concentrar no governo central. Na tabela 2, observa-se que, no federalismo fiscal brasileiro, as transferências são realmente concentradas no governo central (União). Ainda na tabela 2, verifica-se que as transferências intergovernamentais representam 64,4\% e 24,2\% das receitas correntes dos municípios e estados, respectivamente. Em outras palavras, as receitas próprias representam apenas 35,6\% das receitas correntes nos municípios e 75,8\%, nos estados. 
Esses percentuais de receitas próprias denotam a importância das transferências para suprir a brecha fiscal vertical e para equalizar possíveis desequilíbrios horizontais existentes na federação brasileira. Na tabela 3, observa-se que, em 2006, o federalismo fiscal brasileiro transferiu a estados e municípios cerca de R \$ 165 bilhões, ou 6,6\% do PIB. Este montante per se indica a necessidade de se analisar de forma pormenorizada o sistema de transferências intergovernamentais brasileiro, identificando as principais características dessas transferências e os incentivos criados por elas criados.

Essa análise demandaria um longo texto, não sendo, pois, objeto deste artigo. Porém, na tabela 3, aplica-se a taxonomia apresentada na Tabela 1 às transferências vigentes no Brasil em 2006, no intuito de fornecer uma visão geral das características e de incentivos criados por essas transferências.

TABELA 2 - RECEITA CORRENTE NO BRASIL EM 2006, POR ESFERA DE GOVERNO

\begin{tabular}{|c|c|c|c|c|c|c|}
\hline \multirow{2}{*}{$\begin{array}{l}\text { Discrimi- } \\
\text { nação }\end{array}$} & \multicolumn{2}{|c|}{ União } & \multicolumn{2}{|c|}{ Estados } & \multicolumn{2}{|c|}{ Municípios } \\
\hline & $\begin{array}{c}\mathrm{R} \$ \text { mi- } \\
\text { lhões }\end{array}$ & $\%$ & R\$ milhões & $\%$ & $\mathrm{R} \$$ milhões & $\%$ \\
\hline $\begin{array}{l}\text { Receitas } \\
\text { correntes }\end{array}$ & & & & & & \\
\hline & 584.067 & 100,0 & 295.507 & 100,0 & 145.204 & 100,0 \\
\hline $\begin{array}{l}\text { Receitas } \\
\text { próprias }\end{array}$ & 583.880 & 100,0 & 223.895 & 75,8 & 51.733 & 35,6 \\
\hline $\begin{array}{l}\text { Receitas } \\
\text { tributárias }\end{array}$ & 490.242 & 83,9 & 198.966 & 67,3 & 36.603 & 25,2 \\
\hline $\begin{array}{l}\text { Outras } \\
\text { receitas } \\
\text { próprias }\end{array}$ & 93.637 & 16,0 & 24.929 & 8,4 & 15.130 & 10,4 \\
\hline $\begin{array}{l}\text { Transfe- } \\
\text { rências } \\
\text { correntes }\end{array}$ & 188 & 0,0 & 71.612 & 24,2 & 93.471 & 64,4 \\
\hline
\end{tabular}

FONTE: Ministério da Fazenda/Secretaria do Tesouro Nacional (MF/STN). Elaboração dos autores. 
Na tabela 3, observa-se que mais de dois terços das transferências correntes é de propósito geral e incondicional. Essas transferências são instituídas por lei, com boa parte delas definidas na própria Constituição. De fato, as transferências federais para os fundos de repartição de receitas para estados e municípios - FPE e FPM -, que juntos correspondem a cerca de 30\% das transferências correntes, e as partilhas de tributos estaduais do ICMS e IPVA, representando cerca de $20 \%$ das transferências correntes, são definidas na Carta Magna.

Outro grande conjunto de transferências é aquele destinado para propósitos específicos e sem contrapartidas (matching grant). Enquadram-se nesse conjunto as transferências para o SUS, com 12,5\% das transferências correntes; para o FNDE, com 3,2\% das transferências correntes; e para o FUNDEF, atual Fundo Nacional de Desenvolvimento da Educação (FUNDEB), com 15,63\% das transferências correntes.

Cabe mencionar que, no caso do SUS, não é óbvio que as transferências são condicionadas pelo insumo (input), pois parcela importante das transferências desse sistema decorre do número de consultas, cirurgias, entre outros procedimentos que são claros exemplos de produtos (outputs). Assim, é necessário registrar que a opção por enquadrar as transferências do SUS como condicionadas pelo insumo é consequência de a maior parte dessas transferências estarem associadas à aplicação em insumos, visto que decorrem principalmente da oferta de hospitais e de equipamentos existentes nos entes subnacionais.

É válido também destacar que não há dúvida de que as transferências do SUS não são condicionadas pelos resultados (outcomes). A título de ilustração, o sistema de saúde pública brasileiro até tem controle sobre a quantidade de cirurgias cardiovasculares efetivadas, mas não exerce controle algum sobre o incremento na expectativa de sobrevida em decorrência dessas cirurgias. Naturalmente, o controle sobre os resultados deverá ser um caminho a ser seguido, conforme o SUS se aperfeiçoe. 

2006, POR TIPO

Propósito específico

Discriminação

\begin{tabular}{|c|c|c|c|}
\hline \multirow{4}{*}{$\begin{array}{c}\text { Total } \\
\text { consolida- } \\
\text { do (União, } \\
\text { estados e } \\
\text { municípios) }\end{array}$} & \multirow[b]{3}{*}{$\begin{array}{l}\text { Propósito } \\
\text { geral } \\
\text { (Incondi- } \\
\text { cional) }\end{array}$} & \multirow[b]{2}{*}{ Sem contrapartida } & \multirow[b]{2}{*}{ Com contranartida } \\
\hline & & & \\
\hline & & Condicional & $\begin{array}{cc}\text { Condicio- } & \begin{array}{c}\text { Condi- } \\
\text { cional }\end{array} \\
\text { nal } & \text { (limita- } \\
\text { (ilimitada) } & \text { da) } \\
\end{array}$ \\
\hline & & & \\
\hline
\end{tabular}

\begin{tabular}{|c|c|c|c|c|c|c|c|}
\hline Transferências correntes & 165.271 & 125.822 & 39.449 & - & - & - & - \\
\hline $\begin{array}{l}\text { Transferências intergover- } \\
\text { namentais }\end{array}$ & 159.474 & 120.025 & 39.449 & - & - & - & - \\
\hline $\begin{array}{l}\text { Transferências da União } \\
\text { para os estados }\end{array}$ & 61.845 & 44.255 & 17.590 & - & - & - & - \\
\hline Cota-parte do $\mathrm{FPE}^{1}$ & 29.251 & 29.251 & - & - & - & - & - \\
\hline Transferência do SUS & 20.650 & & 20.650 & - & - & - & - \\
\hline Transferências do FNDE ${ }^{2}$ & 2.700 & & 2.700 & - & - & - & - \\
\hline $\begin{array}{l}\text { Transferências do FUN- } \\
\mathrm{DEF}^{3}\end{array}$ & 10.501 & 4.717 & 5.784 & - & - & - & - \\
\hline $\begin{array}{l}\text { Demais transferências da } \\
\text { União }\end{array}$ & 16.701 & 15.004 & 1.697 & - & - & - & - \\
\hline $\begin{array}{l}\text { Transferências da União } \\
\text { para os municípios }\end{array}$ & 46.556 & 29.946 & 16.610 & - & - & - & - \\
\hline Cota-Parte do FPM ${ }^{4}$ & 20.880 & 20.880 & - & - & - & - & - \\
\hline Transferências do FNDE & 2.618 & - & 2.618 & - & - & - & - \\
\hline $\begin{array}{l}\text { Demais transferências da } \\
\text { União }\end{array}$ & 5.099 & 4.348 & 750 & - & - & - & - \\
\hline $\begin{array}{l}\text { Transferências dos esta- } \\
\text { dos para os municípios }\end{array}$ & 40.496 & 40.496 & - & - & - & - & - \\
\hline Cota-Parte do ICMS 5 & 28.398 & 28.398 & - & - & - & - & - \\
\hline Cota-Parte do IPVA ${ }^{6}$ & 5.256 & 5.256 & - & - & - & - & - \\
\hline $\begin{array}{l}\text { Transferências de Recur- } \\
\text { sos do FUNDEF }\end{array}$ & 4.952 & 4.952 & - & - & - & - & - \\
\hline $\begin{array}{l}\text { Outras transferências dos } \\
\text { Estados }\end{array}$ & 1.889 & 1.889 & - & - & - & - & - \\
\hline $\begin{array}{l}\text { Demais transferências } \\
\text { intergovernamentais }^{7}\end{array}$ & 10.578 & 5.329 & 5.250 & - & - & - & - \\
\hline $\begin{array}{l}\text { Demais transferências } \\
\text { correntes }^{8}\end{array}$ & 5.796 & 5.796 & - & - & - & - & - \\
\hline
\end{tabular}


FONTE: MF/STN. Elaboração dos autores. Notas: ${ }^{1}$ FPE: Fundo de Participação dos Estados e Distrito Federal. ${ }^{2}$ FNDE: Fundo Nacional de Desenvolvimento da Educação. ${ }^{3}$ FUNDEF: Fundo de Manutenção e Desenvolvimento do Ensino Fundamental e Valorização do Magistério. ${ }^{4}$ FPM: Fundo de Participação dos Municípios. ${ }^{5}$ ICMS: Impostos sobre Circulação de Mercadorias e Serviços. ${ }^{6}$ IPVA: Imposto sobre a Propriedade de Veículos Automotores. ${ }^{7}$ Inclui as transferências dos municípios para estados /União; as transferências dos estados para a União e aquelas efetuadas por meio de convênio. ${ }^{8}$ Inclui as transferências da sociedade (setor privado) para as esferas de governo.

Nos casos do FNDE e do FUNDEF, atual FUNDEB, é inequívoca a afirmação que se trata de transferências condicionadas pelos insumos, pois são transferências preponderantemente feitas em função do número de alunos matriculados, não sendo condicionas por qualquer tipo de produção ou resultado desses alunos. Ainda na análise da tabela 3, mencione-se a ausência de transferências de propósito específico com contrapartida (matching grant).

Em outras palavras, o federalismo fiscal brasileiro não faz uso de maneira importante de transferências condicionadas ao produto ou de transferências condicionas com contrapartida, as quais, conforme observado no item 2.5, em muitos casos aduzem à accountability e à eficácia dos resultados. De fato, essas transferências são preteridas em função das transferências para propósitos gerais (incondicionais), que se constituem nos maiores exemplos de ineficácia e ausência de accountability.

Essas constatações sugerem que o sistema de transferências intergovernamentais brasileiro não utiliza os tipos mais adequados de transferências para suprir as possíveis brechas verticais e/ou corrigir possíveis desequilíbrios horizontais, havendo, portanto, espaço para melhorias.

\section{Desequilíbrios vertical e horizontal}

\subsection{Brecha Vertical}

Entende-se como brecha fiscal vertical (vertical fiscal gap) a insuficiência financeira resultante da diferença entre a capacidade tributária de um ente público e a necessidade de gastos. Em relação à necessidade real de financiamento, a brecha fiscal diferencia-se tanto pelo lado das receitas quanto pelo das despesas.

Do ponto de vista das receitas, enquanto a necessidade real de financiamento considera as receitas efetivamente arrecadadas, a brecha fiscal estima a capacidade de arrecadação do ente público levando em consideração as bases de tributação disponíveis e as normas legais. Em relação às despesas, passase a considerar não o valor efetivo, mas sim as despesas necessárias para se oferecer um determinado padrão de serviços públicos. 
Necessidade real de financiamento = arrecadação efetiva - despesas efetivas

Brecha fiscal $=$ capacidade de arrecadação - despesas necessárias

Se a concepção teórica é bastante simples, o cálculo da brecha fiscal é, no entanto, uma tarefa relativamente árdua, pois requer a escolha de metodologias para a determinação de seus componentes: capacidade de arrecadação e necessidade de despesas, com a restrição de que essas componentes sejam passíveis de estimação. Por mais óbvio que seja para quem lide com dados federativos, ainda é válido mencionar que, na prática, a disponibilidade de dados fiscais e macroeconômicos para os governos regionais é o maior limitador à adoção de métodos sofisticados.

Com vistas ao cálculo da brecha fiscal, considerou-se como governo regional a união entre um governo estadual e os respectivos governos municipais circunscritos em sua área geográfica legalmente determinada. Essa agregação se justifica, uma vez que ambos os níveis de governo são responsáveis por educação e saúde, que são as atribuições mais dispendiosas para ambos em termos financeiros. Ademais, é comum que programas públicos sejam executados mediante convênios entre o governo estadual e algum dos governos municipais circunscritos em seu raio legal de atuação.

A tabela 5 apresenta as despesas dos governos regionais por função pública em 2006, somando R $\$ 293,8$ bilhões, que correspondem a 12,6\% do Produto Interno Bruto (PIB).

\section{TABELA 4 . DESPESAS DOS GOVERNOS REGIONAIS EM 2006}

\begin{tabular}{lcc}
\hline Função & Despesas (R\$ bilhões) & Despesas (\%) \\
\hline Educação e cultura & 55,8 & 19 \\
Saúde e saneamento & 44,7 & 15 \\
Assistência e previdência & 42,1 & 14 \\
Administração e planejamento & 40,9 & 14 \\
Legislativa e judiciária & 34,9 & 12 \\
Segurança & 28,5 & 10 \\
Transporte & 17,7 & 6 \\
Demais & 29,1 & 10 \\
Total & 293,8 &
\end{tabular}

FONTE: MF/STN. Elaboração dos autores.

No lado da receita, a agregação se justifica pelo fato de a arrecadação com o ICMS e a arrecadação com o IPVA, responsáveis por cerca de 90\% da arrecadação tributária dos governos estaduais, serem transferidos para os governos municipais. De fato, são transferidos aos municípios $25 \%$ da arrecadação com o ICMS e 50\% da arrecadação com o IPVA. Ademais, a arrecadação tributária dos municípios é muito pequena ${ }^{17}$ em relação às suas despesas, as quais, con17 Em 2005, o governo federal arrecadou 22,8\% do PIB, os estados, 9,1\%, e os municípios somente $2 \%$. 
sequentemente, são em sua maioria financiadas por transferências federais e estaduais. Na tabela 5, são apresentadas as receitas de origem tributária dos governos estaduais e municipais e os respectivos valores da arrecadação em 2006, os quais totalizaram R $\$ 237,2$ bilhões ou 10,2\% do PIB.

TABELA 5. TRIBUTOS ESTADUAIS E MUNICIPAIS E ARRECADAÇ

Tributos estaduais e municipais e arrecadação em 2006

\begin{tabular}{|c|c|c|c|}
\hline Tributo & Base de incidência & $\begin{array}{l}\text { Arrecadação } \\
\text { (R\$ bilhões) }\end{array}$ & Arrecadação (\%) \\
\hline \multicolumn{4}{|l|}{ Estaduais } \\
\hline ICMS & Mercadorias e serviços & 165,7 & 83 \\
\hline Contribuições sociais & Salários dos funcionários públicos & 15,8 & 8 \\
\hline IPVA & Propriedade de automóveis & 12,1 & 6 \\
\hline Demais & & 7,1 & 4 \\
\hline Total & & 200,7 & \\
\hline \multicolumn{4}{|l|}{ Municipais } \\
\hline ISS & Serviços & 15,5 & 43 \\
\hline IPTU & Propriedade de imóveis urbanos & 10,3 & 28 \\
\hline Contribuições sociais & Salários dos funcionários públicos & 5,4 & 15 \\
\hline Demais & & 5,3 & 14 \\
\hline Total & & 36,5 & \\
\hline
\end{tabular}

FONTE: MF/STN. Elaboração dos autores.

Vale observar que, nas tabelas acima, assim como no cálculo da brecha fiscal, não se consideraram as despesas financeiras (juros) nem as receitas de capital, que são em grande maioria decorrentes de operações com ativos financeiros e físicos. Além disso, deve-se mencionar que a metodologia de cálculo da brecha fiscal vertical exposta na tabela 6 está no anexo deste artigo.

No caso brasileiro, a diferença entre a capacidade de arrecadação e a arrecadação efetiva está relacionada tanto à concessão de isenções, remissões e subsídios tributários pelos governos estaduais, notadamente os de menor renda per capita, com o objetivo de atrair investimentos de empresas que, em condições normais, instalar-se-iam em outra unidade da federação ("guerra fiscal"), quanto pelas deficiências em termos de recursos materiais e humanos dos órgãos responsáveis pela arrecadação de tributos.

Outro fator determinante da capacidade tributária é a própria composição local da produção de bens e serviços, uma vez que o ICMS, principal tributo 
estadual, não incide uniformemente sobre os diversos bens e serviços. A título de ilustração, alguns serviços, como telecomunicações e distribuição de energia, ou bens manufaturados são muito mais tributados do que produtos agrícolas. Uma vez que, na vigente estrutura tributária, a maior parte do ICMS fica na origem, é natural que estados mais ricos (com maior produção de manufaturados, por exemplo) tenham uma capacidade tributária maior que estados mais pobres (preponderantemente agrícolas).

O nível de despesas é, sobretudo, determinado pela capacidade de financiamento dos governos, seja por meio de receitas próprias, seja por meio de transferências do governo federal e também pelos dispositivos da Constituição Federal que determinam que os governos regionais devem aplicar em educação $25 \%$ das receitas com impostos (não inclui contribuições e taxas) e em saúde $12 \%$ dessas mesmas receitas, no caso dos estados, e 15\%, no caso dos municípios.

Aplicando-se a metodologia exposta no anexo, determinou-se a brecha vertical dos governos regionais em 2006. Observa-se que, em quase todos os estados da região Norte, com exceção do PA, a brecha fiscal é reduzida ou até negativa, em consequência da baixa densidade populacional da região, influenciando o nível de despesas necessárias, e do fato de alguns estados, por serem exterritórios federais, apresentarem um baixo gasto com aposentadorias e pensões de servidores públicos.

No Nordeste, concentram-se os estados com maior brecha fiscal, em consonância com a baixa renda per capita e sua consequente reduzida capacidade tributária. Some-se a isso o baixo IDH presente nos estados nordestinos, que implica grande demanda para a provisão de serviços e assistência social pelo setor público. Ademais, os estados da região Nordeste são os que mais se utilizam do instrumento da "guerra fiscal" para atração de investimentos.

Na região Centro-Oeste, a situação do Distrito Federal destoa da presente nas demais UF por se tratar de uma unidade federada sui generis, devido à condição de capital federal, e, consequentemente, receber elevadas transferências do governo federal de forma indireta, seja pelos salários pagos aos funcionários públicos federais seja pelas empresas que prestam serviços ao governo federal. A região tem uma economia baseada no agronegócio, que vem apresentando elevadas taxas de crescimento nos últimos anos, com impactos positivos sobre a brecha fiscal dos estados de Goiás, Mato Grosso do Sul e Mato Grosso. Vale observar que há uma massa populacional que habita os municípios de Goiás próximos à capital federal, e que lá exerce atividade econômica, distorcendo, de alguma forma, nesse caso específico, as estatísticas de brecha fiscal.

Os estados do Sul e Sudeste apresentam uma brecha fiscal negativa, contrabalançando-se com a região Nordeste. Mencione-se que, em que pese a elevada densidade populacional e a pressão pela oferta de serviços públicos, essas 
regiões concentram grande parcela da atividade econômica. As estimativas da tabela 6 indicam que um desenho de transferências do governo federal para os governos regionais com brecha fiscal positiva, com vistas a moldar a capacidade tributária à necessidade de serviços públicos, teria um custo de $4,4 \%$ do PIB tributável ou de $3,2 \%$ do PIB a preços correntes.

TABELA 6. BRECHA FISCAL VERTICAL EM 2006, POR GOVERNO REGIONAL

\begin{tabular}{|c|c|c|c|c|c|c|c|}
\hline & \multicolumn{3}{|c|}{ Brecha (R\$ bilhões) } & \multicolumn{3}{|c|}{ Brecha $(\% \text { PIB estadual })^{1}$} & \multirow{2}{*}{$\begin{array}{c}\text { Participação } \\
\text { PIB (\%) }\end{array}$} \\
\hline & Receita & Despesa & Total & Receita & Despesa & Total & \\
\hline Norte & 7,00 & 0,43 & 6,57 & 8,89 & 0,54 & 8,34 & 4,7 \\
\hline $\mathrm{AC}$ & 0,43 & 1,34 & $(0,91)$ & 14,8 & 45,9 & $(31,1)$ & 0,2 \\
\hline $\mathrm{AM}$ & 0,12 & 0,12 & 0,00 & 0,5 & 0,5 & 0,0 & 1,5 \\
\hline $\mathrm{AP}$ & 0,49 & 1,00 & $(0,51)$ & 20,9 & 42,8 & $(21,9)$ & 0,1 \\
\hline PA & 4,43 & $(4,61)$ & 9,04 & 14,3 & $(14,9)$ & 29,2 & 1,8 \\
\hline RO & 0,53 & 0,48 & 0,05 & 5,9 & 5,3 & 0,6 & 0,5 \\
\hline $\mathrm{RR}$ & 0,30 & 0,87 & $(0,58)$ & 18,2 & 53,7 & $(35,5)$ & 0,1 \\
\hline TO & 0,70 & 1,23 & $(0,53)$ & 10,2 & 17,8 & $(7,7)$ & 0,4 \\
\hline Nordeste & 35,87 & $(22,87)$ & 58,74 & 17,3 & $(11,0)$ & 28,3 & 12,4 \\
\hline $\mathrm{AL}$ & 2,31 & $(0,98)$ & 3,29 & 22,3 & $(9,4)$ & 31,7 & 0,6 \\
\hline BA & 7,67 & $(7,50)$ & 15,17 & 10,9 & $(10,6)$ & 21,5 & 4,2 \\
\hline CE & 6,16 & $(3,53)$ & 9,68 & 20,0 & $(11,5)$ & 31,5 & 1,8 \\
\hline MA & 4,90 & $(4,80)$ & 9,71 & 24,9 & $(24,4)$ & 49,3 & 1,2 \\
\hline PB & 2,97 & $(1,32)$ & 4,29 & 27,3 & $(12,1)$ & 39,4 & 0,7 \\
\hline PE & 5,99 & $(4,13)$ & 10,11 & 17,0 & $(11,7)$ & 28,8 & 2,1 \\
\hline PI & 2,73 & $(1,23)$ & 3,95 & 35,1 & $(15,8)$ & 50,9 & 0,5 \\
\hline $\mathrm{RN}$ & 2,06 & $(0,01)$ & 2,07 & 16,6 & $(0,1)$ & 16,6 & 0,7 \\
\hline SE & 1,08 & 0,62 & 0,46 & 10,8 & 6,2 & 4,6 & 0,6 \\
\hline Centro-Oeste & $(0,31)$ & 5,54 & $(5,85)$ & $(0,3)$ & 4,5 & $(4,8)$ & 7,3 \\
\hline $\mathrm{DF}$ & $(0,44)$ & 4,23 & $(4,67)$ & $(1,3)$ & 12,1 & $(13,4)$ & 2,1 \\
\hline GO & 1,17 & $(0,78)$ & 1,95 & 2,9 & $(1,9)$ & 4,8 & 2,4 \\
\hline $\begin{array}{l}\text { MS } \\
\text { MT }\end{array}$ & $\begin{array}{r}0,60 \\
(1,65)\end{array}$ & $\begin{array}{l}1,17 \\
0,92\end{array}$ & $\begin{array}{l}(0,56) \\
(2,57)\end{array}$ & $\begin{array}{r}3,8 \\
(5,2)\end{array}$ & $\begin{array}{l}7,3 \\
2,9\end{array}$ & $\begin{array}{l}(3,5) \\
(8,1)\end{array}$ & $\begin{array}{l}1,0 \\
1,9\end{array}$ \\
\hline Sudeste & $(33,80)$ & 17,51 & $(51,31)$ & $(3,5)$ & 1,8 & $(5,3)$ & 58,1 \\
\hline ES & $(0,89)$ & 1,11 & $(2,00)$ & $(2,6)$ & 3,2 & $(5,7)$ & 2,1 \\
\hline MG & 1,39 & $(2,48)$ & 3,87 & 0,9 & $(1,6)$ & 2,5 & 9,2 \\
\hline $\mathrm{RJ}$ & $(4,49)$ & 6,71 & $(11,20)$ & $(2,5)$ & 3,7 & $(6,1)$ & 10,9 \\
\hline SP & $(29,80)$ & 12,18 & $(41,98)$ & $(5,0)$ & 2,0 & $(7,0)$ & 35,8 \\
\hline Sul & $(8,75)$ & $(0,61)$ & $(8,14)$ & $(3,0)$ & $(0,2)$ & $(2,8)$ & 17,5 \\
\hline PR & $(2,51)$ & $(1,91)$ & $(0,60)$ & $(2,4)$ & $(1,8)$ & $(0,6)$ & 6,3 \\
\hline
\end{tabular}


DUARTE, A. J. M. A. \& SILVA, A. M. A. \& LUZ, E. M. \& GERARDO, J. C. Transferências federais no Brasil ...

$\begin{array}{lrrrrrrr}\text { RS } & (2,79) & 0,85 & (3,64) & (2,4) & 0,7 & (3,2) & 6,9 \\ \text { SC } & (3,45) & 0,44 & (3,90) & (4,8) & 0,6 & (5,4) & 4,3 \\ & & & & & & & \\ \text { Soma }^{2} & 46,03 & (33,28) & 73,66 & 2,7 & (2,0) & 4,4 & 100,0\end{array}$

FONTE: Elaboração dos autores. Notas: ${ }^{1}$ PIB tributável = PIB a preços correntes menos os tributos sobre produtos, os serviços públicos gratuitos e os serviços domésticos. ${ }^{2}$ Soma dos valores absolutos.

Em vista do exposto, infere-se que o sistema de transferências intergovernamentais do federalismo fiscal brasileiro não logrou êxito em suprir as brechas verticais em 2006, o que gerou nesse ano um desequilíbrio fiscal vertical, que é a situação na qual a brecha fiscal vertical não é adequadamente tratada, seja pela ausência de redefinição de responsabilidades, seja pela ausência de transferências fiscais dos entes mais favorecidos para os menos favorecidos.

\subsection{Desequilibrio horizontal: o caso do SUS}

Inicialmente, é válido mencionar o porquê da escolha do SUS para avaliação do desequilíbrio horizontal. Dessa forma, destaque-se que, em 2006, as transferências para o SUS totalizaram R \$ 20,65 bilhões, ou o,8\% do PIB, equivalentes a 12,5\% das transferências correntes efetuadas pelas três esferas de governo de forma consolidada. Além disso, mencione-se que o SUS tem como um de seus princípios a equidade, consubstanciada na igualdade da assistência à saúde, sem privilégios de qualquer espécie, segundo o sétimo artigo da lei 8.080 de 1990.

Ademais, no caso das outras transferências condicionadas, em particular no caso do FUNDEF, vários autores já atestaram seu bom desempenho no que diz respeito à correção de desequilíbrios horizontais. ${ }^{18} \mathrm{~A}$ título de ilustração, Mac Dowell \& Gremaud (2005) dizem que: "Em quase todas as Unidades da Federação, o valor das transferências líquidas dividido pelo número de matriculas do ensino fundamental é maior nos quartis inferiores de IDH-M Renda“. Outrossim, como o FUNDEF mudou para FUNDEB, uma avaliação do FNDE ficaria prejudicada pela ausência de elementos no tocante ao total de transferências para educação, ou seja, não seria plausível avaliar o FNDE sem considerar a estrutura de transferências do FUNDEB, haja vista que as transferências para educação são complementares, de modo que devem ser avaliadas conjuntamente.

Por sua vez, no caso das transferências de propósitos gerais (incondicionais), vários trabalhos já sugeriram suas ineficiências e ineficácias. ${ }^{19}$ Assim, em

18 Esta é uma evidência de que não se pode criticar como um todo o vigente sistema brasileiro de transferências fiscais intergovernamentais. A propósito, Shah \& Boadway (2006) incluem o FUNDEF como exemplo de boas práticas, com o objetivo da adoção de padrões mínimos nacionais de acesso a serviços de educação, muito embora, como visto, não sejam transferências condicionadas pelo produto e/ou resultados. 19 A título de ilustração, ver Sousa \& Ramos (1999), Gasparini \& Melo (2004), Guedes \& Gasparini (2007). 
virtude do montante das transferências associadas ao SUS e da maior quantidade de análises concernentes às outras transferências federais, optou-se pela análise do desequilíbrio horizontal do SUS. Nesse sentido, a pergunta que se deseja responder é se as transferências do SUS efetuadas para os estados e os municípios que os compõem são distribuídas de forma a prover às respectivas populações serviços de saúde com um mínimo de qualidade. Assim, a análise das despesas com saúde, incluindo as transferências do SUS, sugere ao menos cinco conclusões:

1) Dos gastos totais com saúde, a União se responsabiliza por, aproximadamente, 50\%; os estados, por 25\%; e os municípios, pelos $25 \%$ restantes, como pode ser observado na Tabela 7 .

TABELA 7. PARTICIPAÇÃO NA DESPESA COM SAÚDE, POR ESFERA DE GOVERNO

\begin{tabular}{lllc}
\hline Ano & União & Estados & Municípios \\
\hline 1980 & 75,0 & 17,8 & 7,2 \\
1985 & 71,7 & 18,9 & 9,5 \\
1990 & 72,7 & 15,4 & 11,8 \\
1995 & 63,8 & 18,8 & 17,4 \\
2000 & 59,8 & 18,5 & 21,7 \\
2001 & 56,1 & 20,7 & 23,2 \\
2002 & 52,8 & 21,5 & 25,6 \\
2003 & 50,4 & 24,5 & 25,2 \\
2004 & 49,9 & 25,6 & 24,5 \\
\hline
\end{tabular}

FONTE: Conselho Nacional de Secretários de Saúde (CONASS 2007). Elaboração dos autores.

2) À exceção da região Norte, com um gasto per capita em torno de $\mathrm{R} \$ 103$, os gastos do SUS per capita (recursos públicos federais transferidos aos estados e aos municípios neles circunscritos) variam relativamente pouco entre regiões, isto é, variam de $\mathrm{R} \$ 114,94$, na região Sudeste, para $\mathrm{R} \$ 119,63$, na região Nordeste, conforme se observa na tabela 8 .

3) A Tabela 8 sugere que, nas transferências do SUS, a União não trata de maneira diferente os desiguais. De fato, percebe-se que estados ${ }^{20} /$ municípios com maior taxa de mortalidade infantil recebem transferências similares às dos estados com indicadores melhores. A título de ilustração, Alagoas, que, em 2006, a cada mil nascimentos, possuía 53,7 mortes de crianças com até 1 ano de idade, recebeu $\mathrm{R} \$ 119,27$, enquanto Rio de Janeiro, que tinha uma taxa de mortalidade infantil de 20,9, recebeu R $\$ 119,26$. 
TABELA 8. MORTALIDADE INFANTIL, COBERTURA DOS PLANOS PRIVADOS DE SAÚDE E TRANSFERÊNCIAS DO SUS

\begin{tabular}{|c|c|c|c|c|c|}
\hline UF & $\begin{array}{l}\text { Taxa de mortalida- } \\
\text { de infantil (\%) }\end{array}$ & $\begin{array}{l}\text { Cobertura de } \\
\text { planos privados } \\
\text { de saúde em } \\
2005(\%)\end{array}$ & $\begin{array}{c}\text { Transferências per } \\
\text { capita ao SUS - } \\
\text { estados }\end{array}$ & $\begin{array}{c}\text { Transferências per } \\
\text { capita ao SUS - } \\
\text { municípios }\end{array}$ & $\begin{array}{c}\text { Transferências } \\
\text { per capita ao } \\
\text { SUS -Total }\end{array}$ \\
\hline Norte & 26,6 & 7,20 & 36,76 & 66,35 & 103,10 \\
\hline PA & 25,9 & 7,65 & 15,17 & 75,82 & 91,00 \\
\hline $\mathrm{AM}$ & 27,6 & 10,25 & 55,92 & 48,40 & 104,32 \\
\hline RO & 25,2 & 4,62 & 39,41 & 67,13 & 106,54 \\
\hline AP & 25,4 & 5,26 & 54,22 & 52,77 & 106,99 \\
\hline $\mathrm{RR}$ & 20,1 & 2,28 & 47,23 & 70,78 & 118,01 \\
\hline $\mathrm{AC}$ & 32,6 & 5,92 & 69,96 & 56,96 & 126,92 \\
\hline TO & 29,0 & 3,28 & 72,84 & 69,22 & 142,06 \\
\hline Nordeste & 38,2 & 8,43 & 34,64 & 84,99 & 119,63 \\
\hline $\mathrm{CE}$ & 32,0 & 9,28 & 27,78 & 84,69 & 112,48 \\
\hline BA & 35,6 & 8,58 & 39,75 & 76,13 & 115,88 \\
\hline MA & 42,1 & 3,82 & 14,49 & 101,48 & 115,97 \\
\hline $\mathrm{AL}$ & 53,7 & 5,82 & 25,76 & 93,51 & 119,27 \\
\hline $\mathrm{RN}$ & 37,5 & 10,56 & 35,83 & 85,37 & 121,20 \\
\hline PE & 41,2 & 12,44 & 59,63 & 62,56 & 122,18 \\
\hline SE & 36,2 & 8,86 & 29,19 & 94,26 & 123,44 \\
\hline PB & 40,8 & 8,15 & 20,97 & 112,33 & 133,29 \\
\hline$\underline{\mathrm{PI}}$ & 30,4 & 4,19 & 28,46 & 107.97 & 136,43 \\
\hline Sudeste & 18,9 & 31,73 & 53,15 & 66,33 & 119,48 \\
\hline MG & 21,8 & 19,19 & 31,45 & 79,09 & 110,54 \\
\hline ES & 20,1 & 21,42 & 68,37 & 48,36 & 116,73 \\
\hline RJ & 20,9 & 31,93 & 55,68 & 63,58 & 119,26 \\
\hline $\mathrm{SP}$ & 16,5 & 38,48 & 61,21 & 62,83 & 124,04 \\
\hline$\underline{\text { Sul }}$ & 17,2 & 17,42 & 43,67 & 71,27 & 114,94 \\
\hline RS & 14,3 & 16,34 & 39,07 & 65,12 & 104,19 \\
\hline $\mathrm{SC}$ & 17,2 & 17,87 & 42,20 & 75,54 & 117,74 \\
\hline PR & 20,0 & 18,30 & 49,36 & 75,32 & 124,68 \\
\hline $\begin{array}{l}\text { Centro- } \\
\text { Oeste }\end{array}$ & 20,1 & 12,81 & 42,39 & 73,06 & 115,45 \\
\hline
\end{tabular}




\begin{tabular}{lrrrrr}
\hline DF & 17,8 & 26,01 & 101,90 & - & 101,90 \\
GO & 20,7 & 8,81 & 21,52 & 87,94 & 109,46 \\
MT & 21,6 & 8,83 & 42,36 & 78,84 & 121,19 \\
MS & 19,1 & 14,06 & 32,77 & 104,56 & 137,33 \\
\hline & & & & \\
Brasil & 25,8 & 19,88 & 44,57 & 72,69 & 117,25 \\
\hline
\end{tabular}

FONTES: Instituto Brasileiro de Geografia e Estatística (IBGE), Síntese de Indicadores Sociais - 2006. Departamento de Informática do SUS - Datasus/ 2006. Elaboração dos autores.

4) Na Tabela 8, observa-se que os estados com maior taxa de mortalidade infantil também apresentam menor cobertura de planos privados de saúde. Em outras palavras, o setor privado está relativamente menos presente naqueles estados que apresentam maior necessidade de gastos com saúde. Assim, estados com maior taxa de mortalidade infantil e menor cobertura de plano de saúde privado são tratados de maneira similar aos que têm baixa mortalidade infantil e alta cobertura da saúde privada. ${ }^{21}$

TABELA 9. TOTAL DOS GASTOS DO SUS PER CAPITA COM PROCEDIMENTOS DE ATENÇÃO BÁSICA (BAIXA COMPLEXIDADE') EM 2006

\begin{tabular}{lcccccc}
$\begin{array}{l}\text { Decis/ } \\
\text { Região }\end{array}$ & Brasil & NO & NE & SE & SUL & CO \\
\hline 1 & & & & & & \\
2 & 45,3 & 53,5 & 51,8 & 41,9 & 47,8 & 49,8 \\
3 & 45,0 & 46,7 & 48,2 & 40,7 & 51,2 & 50,6 \\
4 & 46,2 & 54,1 & 56,5 & 41,8 & 36,4 & 52,3 \\
5 & 46,4 & 50,0 & 43,8 & 33,8 & 34,2 & 48,5 \\
6 & 43,4 & 48,8 & 59,7 & 36,5 & 44,7 & 42,1 \\
7 & 51,9 & 43,0 & 53,9 & 35,7 & 36,8 & 52,8 \\
8 & 35,0 & 42,5 & 50,8 & 26,7 & 29,3 & 36,0 \\
9 & 30,0 & 44,7 & 48,6 & 21,3 & 25,3 & 33,0 \\
10 & 22,4 & 34,9 & 51,3 & 14,6 & 15,9 & 18,3 \\
& 8,3 & 21,8 & 19,7 & 4,9 & 5,9 & 8,4 \\
\hline
\end{tabular}

FONTES: Pesquisa Nacional por Amostra de domicílios (PNAD)/2006 e Departamento de Informática do SUS - Datasus/ 2006. Elaboração dos autores.

Nota: ${ }^{1}$ Baixa complexidade: consulta médica; consulta odontológica; consulta de comunitário ou de parteira, consulta de outros profissionais de saúde (fonoaudiólogos, psicólogos etc.).

21 . Na análise para o indicador esperança de vida, as conclusões são similares, haja vista que a correlação negativa entre os indicadores mortalidade infantil e esperança de vida é da ordem de 0,95 . 


\begin{tabular}{lcccccc}
$\begin{array}{l}\text { Decis/ } \\
\text { Região }\end{array}$ & Brasil & NO & NE & SE & SUL & CO \\
& & & & & & \\
\hline 1 & 55,9 & 70,4 & 57,9 & 67,1 & 98,9 & 69,0 \\
2 & 80,0 & 58,9 & 57,6 & 111,4 & 109,3 & 45,6 \\
3 & 66,0 & 27,0 & 81,4 & 128,0 & 38,4 & 106,0 \\
4 & 109,5 & 46,9 & 22,9 & 76,0 & 102,3 & 99,6 \\
5 & 78,8 & 44,1 & 75,9 & 119,5 & 182,5 & 54,4 \\
6 & 133,1 & 54,1 & 83,8 & 153,6 & 86,1 & 108,1 \\
7 & 103,9 & 56,3 & 101,5 & 97,8 & 46,6 & 90,4 \\
8 & 83,4 & 111,0 & 108,0 & 89,1 & 59,4 & 146,9 \\
9 & 87,5 & 105,7 & 84,1 & 59,9 & 118,9 & 54,6 \\
& & & & & & \\
10 & 33,3 & 30,0 & 61,5 & 41,3 & 5,2 & 9,6 \\
& & & & & & \\
\hline
\end{tabular}

FONTES: PNAD/2006 e Departamento de Informática do SUS - Datasus/ 2006. Elaboração dos autores.

Nota: ${ }^{1}$ Alta e média complexidade: internação hospitalar; cirurgia em ambulatório; quimioterapia, radioterapia, hemodiálise, hemoterapia; gesso ou imobilização.

5) Além de não ser equitativo na distribuição de recursos, o SUS também é utilizado de maneira diferente entre pobres e ricos. De fato, os pobres $\left(1^{\circ}, 2^{\circ} \mathrm{e}\right.$ $3^{\mathrm{o}}$ décimos de renda) se beneficiam mais dos procedimentos de atenção básica (baixa complexidade), enquanto os ricos $\left(8^{\circ}, 9^{\circ}\right.$ e $10^{\circ}$ décimos de renda) se beneficiam mais dos procedimentos de média/alta complexidade, conforme se observa nas tabelas 9 e 10.

No caso do item 5, deve-se observar que os procedimentos de baixa complexidade são bem menos caros para o setor público que os procedimentos de alta e média complexidade. Isso sugere que os ricos utilizam os planos de saúde para as consultas ambulatoriais, contudo, no momento de efetuar um procedimento mais complexo, tipo cirurgia ou quimioterapia, procuram o SUS. Mais uma vez, parece não haver equidade na distribuição dos recursos do SUS.

\section{Considerações Finais}

Neste artigo, objetivou-se prover uma contribuição ao federalismo fiscal brasileiro. Nesse sentido, especificamente, identificou-se de que modo as transferências do governo federal realizadas em 2006 supriu a brecha fiscal vertical. Além disso, analisou-se se há desequilíbrio horizontal nas transfe- 
rências para a consecução do Sistema Único de Saúde, i.e, analisou-se se os serviços públicos de saúde são oferecidos de forma heterogênea entre os entes subnacionais do Brasil.

Em relação à brecha fiscal vertical de 2006, inferiu-se que o sistema de transferências intergovernamentais do federalismo fiscal brasileiro não logrou êxito em supri-la, o que gerou nesse ano um desequilíbrio fiscal vertical, que é a situação na qual a brecha fiscal vertical não é adequadamente tratada, seja pela ausência de redefinição de responsabilidades, seja pela ausência de transferências fiscais dos entes mais favorecidos para os menos favorecidos

No que diz respeito à análise de desequilíbrio horizontal do SUS, verificou-se que a oferta de serviço público de saúde é feita de maneira desigual no Brasil. De fato, estados relativamente ricos possuem oferta de serviço público melhor do que estados relativamente pobres. Em outras palavras, o SUS não é equitativo na distribuição de seus recursos, i.e, não trata situações desiguais de formas desiguais.

\section{Referências}

BLANCO, F.(2000) "Comportamento fiscal dos governos estaduais brasileiros, determinantes políticos e efeitos sobre o bem-estar”. In ENCONTRO NACIONAL DE ECONOMIA, 28., 2000. Campinas, SP. Anais. Campinas: ANPEC.

CONASS.(2007) "Para entender a gestão do SUS". Progestores (Programa de informação e apoio técnico as novas equipes gestoras estaduais), Brasília: DF: 2007. URL: <http://portal.saude.sp.gov.br/resources/gestor/destaques/ colecao_progestores/livro3.pdf> Acesso em: 06 de junho de 2008.

GASPARINI, C. E. \& MELO, C. S. L. de. (2004) "Equidade e eficiência municipal: uma avaliação do fundo de participação dos municípios - FPM.” In: TESOURO NACIONAL (org.). Finanças Públicas. Brasília: Editora Universidade de Brasília, v. 8, p. 337-401.

GIAMBIAGI, F. \& ALÉM, A. C.(2008)Finanças públicas: teoria e prática no Brasil, capítulo 12. Editora Campus.

GUEDES, K. \& GASPARINI, C. E.(2007) Descentralização fiscal e tamanho do governo no Brasil. Revista de Economia Aplicada, São Paulo - SP, v. 11(2): 303-323.

MAC DOWELL, M. C. \& GREMAUD, A. (2005) “Transferências intergovernamentais como elemento de coordenação federativa.” In Congreso Internacional del Clad sobre la Reforma del Estado y de la Administración Pública,10., Santiago, Chile. Anais... Santiago, Chile.

MCLURE JR., C. E. (1983) (Org.). Tax assignment in federal countries. Canberra: Australian National University.

MENDES, M. J. (2005) "Federalismo Fiscal In" Economia do Setor Público no Brasil. BIDERMAN, C.; Arvate, P. (orgs). Editora Campus.

MUSGRAVE, R. A.(1959) The theory of public finance: a study in public economy. New York: McGraw-Hill. 
OATES, W. E. (1972) Fiscal Federalism. Nova York: Harcourt Brace Jovanovich.

RESENDE, G. M. \& SILVA, A. M. A. (2007) “Crescimento econômico dos municípios da região Sul do Brasil: uma análise espacial.” Ensaios FEE 28: 549-575.

SHAH, A. \& BOADWAY, R. (2006) Intergovernmental fiscal transfers principles and practice. Washington, DC.: World Bank.

SOUSA, M. C. S. \& RAMOS, F. S. (1999) "Eficiência técnica e retornos de escala na produção de serviços públicos municipais: o caso do Nordeste e do Sudeste brasileiros”. Revista Brasileira de Economia 53 (4): 433-461.

TIEBOUT, C. M. (1956) “A pure theory of local expenditures.” Journal of Political Economy 64: 416-424.

ANEXO

\section{METODOLOGIA DE CÁLCULO DA BRECHA FISCAL VERTICAL ${ }^{22}$}

A brecha fiscal foi determinada calculando-se separadamente: $i$ ) as equalizações de receitas necessárias a cada um dos governos regionais, que correspondem à diferença entre as respectivas capacidades tributárias e o nível (alíquota) de tributação média entre as unidades federativas; e ii) as equalizações de despesas para cada um dos governos regionais, que é a diferença entre a despesa média per capita nacional e a despesa média per capita na respectiva unidade da federação.

Algebricamente, temos:

$$
E R_{m}^{i}=P O P^{i}\left(R P_{m}^{n a}-R P_{m}^{i} \times t_{m}^{n a} / t_{m}^{i}\right)
$$

em que $E R_{m}^{i}$ e $R P_{m}^{i}$ significam, respectivamente, equalização de receitas e receita per capita do estado $i$ referente à base tributária $m$; $P O P$ a população; e $t$ o valor empírico da alíquota de tributação, que foi determinado pela razão entre os valores da arrecadação e da respectiva base de tributação. $\mathrm{O}$ sobrescrito na corresponde à média nacional.

$$
E D_{n}^{i}=P O P^{i}\left(D P_{n}^{n a}-D P_{n}^{i}\right)
$$

em que $E D_{n}^{i}$ e $D P^{i}{ }_{m}$ significam, respectivamente, equalização de despesas e 22 Essa metodologia baseia-se na metodologia apresentada nas páginas 25 a 30 de Shah \& Boadway (2006). 
despesa per capita do estado $i$ referente à função pública $n$.

$$
B^{i}=\Sigma_{m=1}^{M} E R_{m}^{i}+\Sigma_{n=1}^{N} E D_{n}^{i}
$$

em que $B^{i}$ é a brecha total na unidade federativa $i$.

Obviamente, para o cálculo da brecha de despesas, a adoção, como referência, de níveis de gastos nas principais funções públicas determinados pelo custo em se prover os serviços públicos em padrões mínimos, tanto em quantidade como em qualidade, seria mais adequado do que estabelecer a média nacional como referencial. Infelizmente, ainda não dispomos, no Brasil, de estimativas confiáveis do custo associado à oferta dos serviços nesse padrão mínimo a ser adotado, assim como algum nível de consenso em torno de qual deva ser o próprio padrão mínimo.

A partir de dados das contas nacionais dos estados, construímos uma base de tributação para o Imposto sobre Circulação de Mercadorias e Prestação de Serviços (ICMS), abrangendo o valor agregado na agricultura, indústria, com exceção da construção civil, serviços de utilidade pública, comércio e telecomunicações; e uma outra base para o Imposto sobre Serviços (ISS), que corresponde ao valor dos serviços produzidos, excetuando os serviços públicos gratuitos, os domésticos e os já incluídos na base do ICMS. Adotou-se o PIB a preços básicos, ${ }^{23}$ reduzido dos serviços públicos gratuitos e domésticos, como proxy da base dos demais tributos.

Em seguida, calculou-se a equalização para cada unidade correspondente ao ICMS, ao ISS e às demais fontes de receitas tributárias, separadamente. Não foram consideradas nos cálculos outras receitas correntes (não tributárias) e as receitas de capital.

No cálculo da equalização de despesas com educação, considerou-se apenas a população até 17 anos, porém para o cômputo da equalização de despesas com as demais funções públicas utilizou-se a população total. O tratamento diferenciado com a educação se deve ao fato de que, constitucionalmente, os estados e municípios devem atuar prioritariamente na educação básica e o governo federal na educação superior. Ademais, não consideramos as despesas de capital.

Recebido em: 27 de dezembro de 2009

Primeira resposta em: 16 de março de 2010

Aceite em: 23 de novembro de 2009

23 Em 2006, o PIB brasileiro a preços de mercado foi de R\$ 2.333 bilhões, e a preços básicos, ou seja, excluindo os tributos sobre produtos, foi de R\$2.001 bilhões. 